\title{
BMJ Open Correlates of intended COVID-19 vaccine acceptance across time and countries: results from a series of cross- sectional surveys
}

\author{
John R Kerr (D) , ${ }^{1,2}$ Claudia R Schneider (D) , , ${ }^{1,2}$ Gabriel Recchia (D) , 1 \\ Sarah Dryhurst (D) , ${ }^{1}$ Ullrika Sahlin (1) , ${ }^{3}$ Carole Dufouil (D) , ${ }^{4,5}$ Pierre Arwidson, ${ }^{6}$ \\ Alexandra LJ Freeman (D), ${ }^{1}$ Sander van der Linden (iD ${ }^{2}$
}

To cite: Kerr JR, Schneider CR, Recchia G, et al. Correlates of intended COVID-19 vaccine acceptance across time and countries: results from a series of crosssectional surveys. BMJ Open 2021;11:e048025. doi:10.1136/ bmjopen-2020-048025

- Prepublication history and additional supplemental material for this paper are available online. To view these files, please visit the journal online (http://dx.doi.org/10.1136/ bmjopen-2020-048025).

Received 21 December 2020 Accepted 08 July 2021
Check for updates

(C) Author(s) (or their employer(s)) 2021. Re-use permitted under CC BY-NC. No commercial re-use. See rights and permissions. Published by BMJ.

For numbered affiliations see end of article.

Correspondence to

Dr John R Kerr;

jk802@cam.ac.uk

\section{ABSTRACT}

Objective Describe demographical, social and psychological correlates of willingness to receive a COVID-19 vaccine.

Setting Series of online surveys undertaken between March and October 2020.

Participants A total of 25 separate national samples (matched to country population by age and sex) in 12 different countries were recruited through online panel providers $(n=25334)$.

Primary outcome measures Reported willingness to receive a COVID-19 vaccination.

Results Reported willingness to receive a vaccine varied widely across samples, ranging from $63 \%$ to $88 \%$. Multivariate logistic regression analyses reveal sex (female $\mathrm{OR}=0.59,95 \% \mathrm{Cl} 0.55$ to 0.64$)$, trust in medical and scientific experts (OR=1.28, $95 \% \mathrm{Cl} 1.22$ to 1.34$)$ and worry about the COVID-19 virus (OR=1.47, 95\% $\mathrm{Cl} 1.41$ to 1.53) as the strongest correlates of stated vaccine acceptance considering pooled data and the most consistent correlates across countries. In a subset of UK samples, we show that these effects are robust after controlling for attitudes towards vaccination in general. Conclusions Our results indicate that the burden of trust largely rests on the shoulders of the scientific and medical community, with implications for how future COVID-19 vaccination information should be communicated to maximise uptake.

\section{INTRODUCTION}

COVID-19 has resulted in over 2.5 million deaths globally, illness for millions more and unprecedented social and economic disruption. ${ }^{12}$ Many governments have signalled that mass vaccination against the virus is the most straightforward-and possibly only-route to normality and stability. ${ }^{3} 4$ While recent announcements of effective vaccines ${ }^{56}$ and their rollout to certain demographics in some countries are promising, ${ }^{7}$ the wider impact of vaccines on preventing the spread of disease is dependent on broad uptake within a given population. In order to achieve 'herd
Strengths and limitations of this study

- To examine predictors of vaccine acceptance, we collected data from a large number of participants in several different countries and at different time points.

- We examine a range of demographical, risk and trust-related predictors using multivariate models.

- Samples were quota matched (age and gender) to country population, but not probability sampled.

- At the time of the surveys, no COVID-19 vaccine was publicly available; thus, stated acceptance is hypothetical and may change with provision of more information about current vaccines.

immunity', enough people in a population must be immune to prevent the spread of a disease among non-immune individuals. The proportion varies depending on a number of factors including how infectious the contagion is, its prevalence in a population and the variation in individual susceptibility or exposure to infection. ${ }^{8}$ Estimates for the level of immunity required for COVID-19 herd immunity have ranged from $50 \%$ to $80 \%$ of the population, acquired through either natural infection and recovery or vaccination. ${ }^{9}{ }^{10}$ It must be noted that, while there is evidence that currently available vaccines can reduce SARS-CoV-2 infections, ${ }^{11}$ there is only limited preliminary evidence that vaccination can reduce transmission of the virus at the time of writing. ${ }^{12}$ Thus, the net impact of vaccination campaigns on the spread of the virus remains uncertain until more research is conducted. ${ }^{13}$

Vaccine hesitancy-defined as a delay in acceptance or refusal of vaccines despite availability ${ }^{14}$ _ poses a challenge to achieving herd immunity. If a sufficient number of people in a population reject vaccination-and herd 
immunity is not achieved-the virus will continue to circulate among susceptible individuals, including those who are unable to be vaccinated for medical reasons. The WHO identified vaccine hesitancy as one of the top 10 threats to global health in $2019,{ }^{15}$ and in the pressing context of COVID-19, understanding vaccine hesitancy has only grown in importance. ${ }^{16}$

Public health researchers concerned with uptake of vaccination have understandably sought to uncover the drivers of vaccine hesitancy. By identifying antecedents of vaccine hesitancy, policy makers, public health officials and professional communicators can target interventions to increase uptake of vaccines and ultimately reduce the burden of disease in a population. ${ }^{4}$ However, strategies developed for campaigns targeting diseases with well-established vaccines (eg, measles, mumps and rubella (MMR) and pertussis) may not fully translate to a pandemic context where there is greater uncertainty and less information available and where institutional trust plays a greater role-as was noted in the wake of the 2009 H1N1 influenza pandemic. ${ }^{17}$

Recent evidence shows that acceptance of a COVID-19 vaccine is far from universal in many countries. Lazarus et $a l^{18}$ conducted a series of surveys across 19 countries in June 2020, asking respondents how much they agreed with the following statement: 'If a COVID-19 vaccine is proven safe and effective and is available, I will take it'. The proportion of respondents who agreed ranged from $88.6 \%$ (China) to $55.8 \%$ (Russia). Examining possible predictors of vaccine acceptance, the authors report that men, older people and those who express greater trust in the government were more likely to express willingness to receive a vaccine. The role of trust (in science, the government or the medical system) is a recurring theme in many other recent studies, which have examined COVID-19 vaccine hesitancy in individual countries. ${ }^{19-27}$ For example, Palamenghi $e t a l^{24}$ report that across two large random samples of the Italian population, trust in science was positively correlated $(r=0.37)$ with willingness to receive a COVID-19 vaccine. Frank and Arim ${ }^{20}$ report that Canadians who are more trusting of local and national government bodies are more likely to express intentions to receive a vaccine if available, as are those who report high general social trust (ie, believing that 'most people can be trusted').

Such results align with pre-COVID studies that have highlighted the role of trust in vaccination intentions and attitudes. ${ }^{17829}$ However, we note that recent studies examining COVID-19 vaccine intentions have typically only examined trust in one entity (eg, government or hospitals); research to date has not considered the possible overlap between trust in the government, trust in science and medicine and general social trust. ${ }^{30-32}$ There is also a question over the extent to which vaccine acceptance is linked to mistrust in experts and authorities regarding COVID-19 in particular or a more general lack of trust in these actors. In order to target communications specifically designed to satisfy the information needs of those who distrust official authorities, it is important to identify the precise agents that they distrust (and, ideally, why).

Beyond trust, the perceived threat or risk posed by a given disease has also been shown to predict vaccination attitudes. Models of health behaviour, such as the health belief model $^{33}$ and protection motivation theory ${ }^{34}$, place the perceived risk or severity of a disease as a key driver of vaccination intentions (and other preventative health behaviours). ${ }^{1735}$ Recent surveys in the USA, Malaysia and Israel have shown that perceived risk and worry regarding the COVID-19 virus are associated with vaccine acceptance. ${ }^{36-38}$ Other factors, such as the perceived benefits and costs as well as efficacy of protective behaviours, are also outlined in models of health behaviour as predictors of engagement in a given health behaviour. However, until recently, little information about the possible costs, distribution and efficacy of a COVID-19 vaccine was available, meaning that the public has not generally been able to assess the potential benefits of a vaccine outside of a purely hypothetical arena (although experimental work has examined the influence of these factors on willingness to receive a vaccine ${ }^{39}$ ).

There are also increasing concerns about the politicisation of science and about politics becoming entangled with vaccine beliefs and attitudes specifically, particularly in the context of a pandemic where central government structures are deeply involved in all stages of the public health response. ${ }^{17} 40$ Prior research ${ }^{41}$ has shown that the rhetoric adopted by political elites on social media can fuel antivaccination attitudes among their followers and that ideologies can help explain antivaccination attitudes. $^{3742}$

In the current study, we present a more comprehensive international analysis of the role of key social, political and psychological correlates of COVID-19 vaccine acceptance across 12 countries, with multiple national surveys in some countries (total $n=25334$; see table 1 ). All samples were recruited via online panel providers using quotas to ensure samples were matched to the general population in terms of age and gender (with the exception of France; see Methods section). Unlike previous studies, we examine reported trust in a range of actors, both in general and specifically relating to the COVID-19 pandemic. We also include several demographical factors (including political orientation); numeracy (known to play a role in risk perceptions ${ }^{43}$ and vaccine attitudes in particular ${ }^{44}$ ); affective (worry) and cognitive (perceived likelihood of infection) aspects of perceived COVID-19 risk $^{45}$; broad measures of perceived efficacy; and, in a subset of samples, general attitudes towards vaccines.

\section{METHODS}

\section{Participants and procedure}

Between March and October 2020, we fielded 25 separate surveys across 12 countries. The majority of samples were recruited through an ISO-certified international survey company Respondi (respondi.com). Our initial 


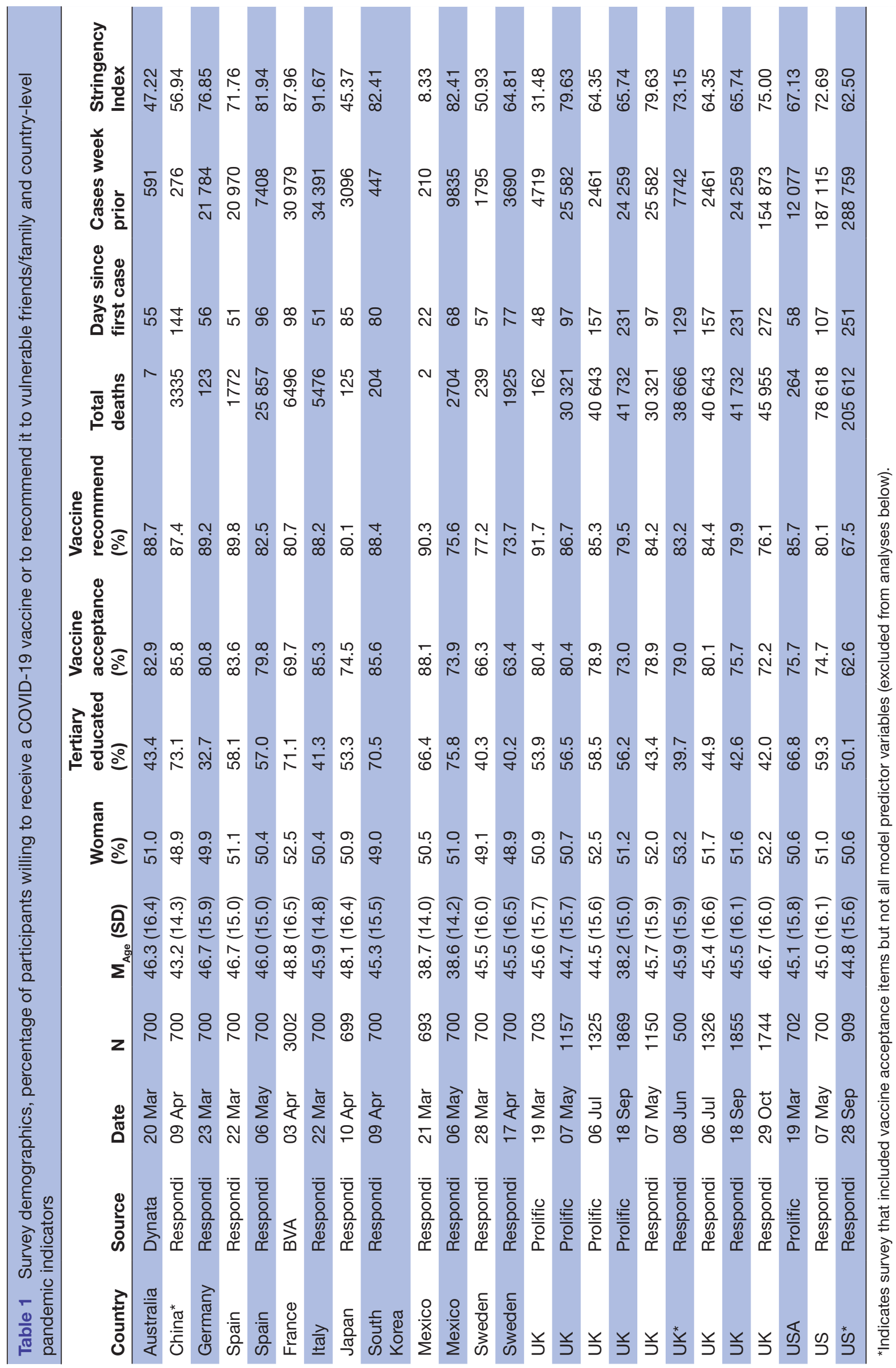


US and UK samples were recruited via Prolific (prolific. ac). Although some later samples from these countries were recruited via Respondi, we continued to also recruit Prolific samples to allow comparisons with our earliest data points in the pandemic. As we did not have matching Prolific and Respondi samples at each time point and results differed slightly between these providers, we report these samples separately for transparency. Recruitment was managed by these external providers, and exact response rates were not provided. However, Respondi provided a broad estimate of a $30 \%$ response rate across surveys (personal communication; Respondi, 2021). Nonresponse bias was mitigated by quota-based sampling, which ensured all samples were representative of each country's population in terms of age and gender (using interlocking quotas based on national census data) and, in Prolific samples, ethnicity. ${ }^{46}$ We also control for sociodemographic factors such as education level and political orientation in analyses below. Participants who had previously completed a survey were prevented from completing further surveys, so all our samples represent different individuals. Participants who did not finish the survey were excluded. Demographical details for each sample are shown in table 1. For completeness, we include several samples in which vaccine acceptance was measured, but the survey did not include all the independent variables used in the models presented below. Surveys that did not include all these variables are marked with a '*' in table 1 .

All participants were directed via a study link to the Qualtrics platform and provided informed consent before completing the survey. This study was approved by the University of Cambridge psychology research ethics committee (PRE.2020.034).

It is important to note that the surveys were conducted at various time points as the pandemic unfolded in each country. Table 1 also reports the total number of COVID-19 deaths for each country at each survey time point and the number of reported cases in the week prior to the survey (with the caveat that reporting practices vary between countries). We also provide the Stringency Index measure generated by the COVID-19 Government Response Tracker, ${ }^{47}$ which is a $0-100$ index based on various restrictions put in place by governments to control the pandemic (eg, closing schools and 'shelter in place' requirements). External data were sourced from the COVID-19 Government Response Tracker ${ }^{47}$ and Ali et $a l^{48}$

The information about potential vaccines also changed over the data collection period. In February 2020, the first major vaccine candidates, the Moderna and OxfordAstraZeneca vaccines, were announced. ${ }^{49}{ }^{50}$ In mid-2020, the launches of phase III trials for several vaccines were announced: Moderna and Pfizer-BioNTech in July ${ }^{51}$ and AstraZeneca in August. ${ }^{52}$ Results of phase III clinical trials and estimates of efficacy were not announced during the data collection period (ending in October 2020). No vaccines were approved for use by local regulators at the time(s) the surveys were conducted in each country.

\section{Materials}

Participants reported their age and gender, level of education (ranging from no formal education above age 16 to $P h D$ ) and political orientation (very liberal/left wing to very conservative/right wing). Numeracy was measured as a combined index of the 2-3-item adaptive form of the Berlin Numeracy Test ${ }^{53}$ and an additional risk literacy item from Lipkus et $a l^{54}$

Participants completed a widely used measure of general social trust (generally speaking, would you say most people can be trusted or that you can't be too careful in dealing with people? $)^{55}$ and a separate measure of prosociality (to what extent do you think it's important to do things for the benefit of others and society even if they have some costs to you personally?). Trust in experts and trust in the government were each measured as the combined average of reported trust in three targets (experts: scientists, medical doctors and nurses and scientific knowledge (Cronbach's as: 0.77-0.86); government: politicians, current government and civil servants (Cronbach's $\alpha$ s: 0.73-0.90); and all from cannot be trusted at all to can be trusted a lot). We also asked participants to report their trust in several actors with specific regard to the COVID-19 pandemic. Participants reported the extent to which they trust politicians in their country to 'deal effectively with the pandemic' and how much they separately trusted the country's national scientific and medical advisors, independent experts not connected with the government and the WHO to 'know the best measures to take in the face of the pandemic' (all from not at all to very much). Personal and government efficacy were captured by items asking participants the extent to which they felt that, respectively, their own actions and the actions of their country 'to limit the spread of coronavirus can make a difference' (not at all to very much). Perceived likelihood of infection was measured as an index of three related items (example: $I$ will probably get sick with the coronavirus/COVID-19; Cronbach's $\alpha s$ : 0.71-0.89). Participants also reported their level of worry about the virus (from not at all worried to very worried). In a subset of UK samples, we also asked participants about their general attitude towards vaccination, using two items from Lewandowsky $e t a l{ }^{42}$ scale (example: I believe that vaccines are a safe and reliable way to help avert the spread of preventable diseases (Pearson's rs: 0.83-0.87).

Participants' vaccine acceptance was measured with the following question: 'If a vaccine were to be available for the coronavirus/COVID-19 now, would you get vaccinated yourself?' (yes/no). Participants were also asked, 'If a vaccine were to be available for the coronavirus/COVID-19 now: Would you recommend vulnerable friends/family to get vaccinated?' (yes/no). Full-item wording for all measures can be found in online supplemental table S1.

Surveys were translated from English to other languages by native speakers fluent in English. 


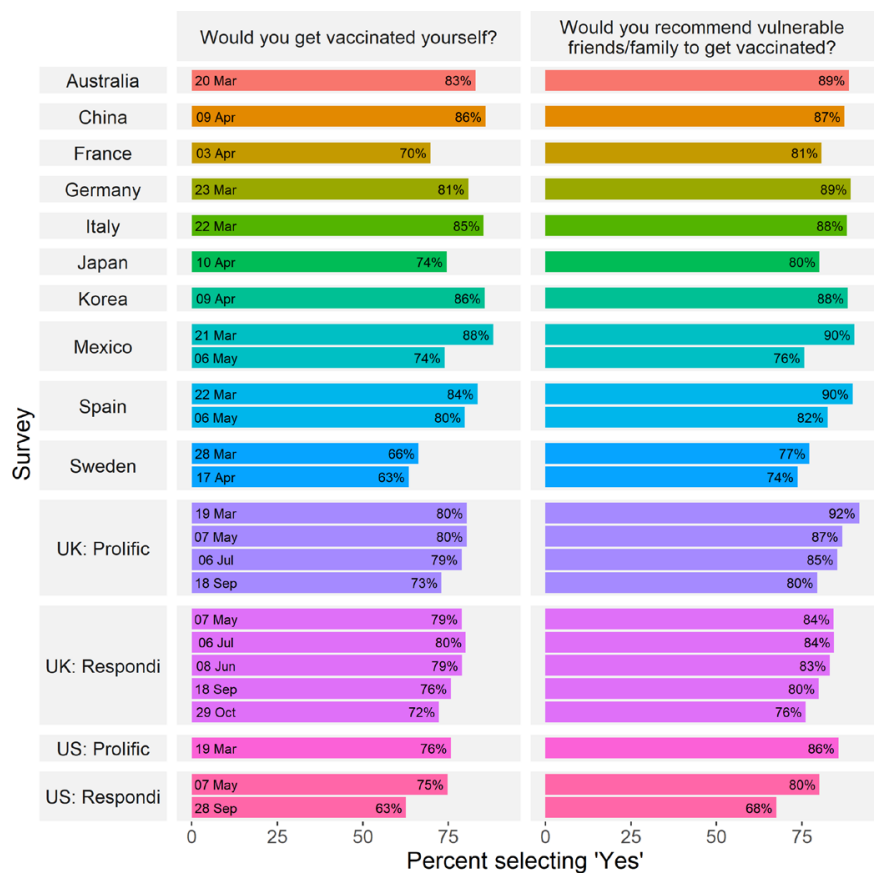

Figure 1 COVID-19 vaccine acceptance across countries and time. Percentage of respondents who stated they were willing to receive or recommend a COVID-19 vaccine across surveys. UK and US samples using different panel providers are reported separately.

\section{Analysis}

To examine the correlates of vaccine acceptance, we fitted a multivariate logistic regression model to the data from each survey. To allow for descriptive comparisons between countries and across time, we report model results separately for each country, time point and (in the UK) panel provider. We also report results from the model fitted to the pooled data from all surveys and a supplementary multilevel model adjusting for survey-level variables (total number of cases and days since the first case in the country at time of survey). All analyses were conducted in $\mathrm{R}$ (V.4.0.5).

\section{RESULTS}

Figure 1 shows the percentage of participants in each survey who responded that they would be willing to be vaccinated if a COVID-19 vaccine was available or would recommend a vaccine to vulnerable others, given the options of 'yes' or 'no' (based on respondents who answered the question). In the Italy sample, a number of participants were not presented with these items due to a technical error $(n=80,11 \%)$. In the remaining samples, the average proportion of missing responses for vaccine intention and recommendation items was $1 \%$ (see online supplemental tables S2 and S3 for description of missing data and the age and gender distribution of those participants who answered the vaccine acceptance item). We acknowledge that in some cases, estimates of vaccine acceptance may not be based on samples exactly matched to a country's population age and gender distribution due to this missing data, but note that age and gender are controlled for in the models below. Across all samples, the percentage of respondents who stated they were willing to receive a vaccine ranged from $62.6 \%$ (Sweden, April) to $88.1 \%$ (Mexico, March), while the percentage of those who said they would recommend a vaccine to vulnerable others ranged from $67.5 \%$ (the USA, September) to $91.7 \%$ (the UK, March). Descriptively, in every single sample, the proportion of respondents stating a willingness to receive a vaccine was lower than the proportion who would recommend it to vulnerable others $\left(M_{\text {diff }}=-5.79 \%, \mathrm{SD}=3.00\right)$. We also note a trend of decreasing stated acceptance over time: in nearly all countries with multiple samples, vaccine acceptance in any given survey was lower than previous surveys of the same population. For example, between March and May 2020, stated vaccine acceptance among respondents in Mexico dropped from $88.1 \%$ to $73.9 \%$ (a $\chi^{2}$ test of independence indicated that this difference was statistically significant, $\left.\chi^{2}=42.44, p<0.001\right)$ In the USA, stated vaccine acceptance (among participants recruited through online panel provider Respondi) fell more than 12 percentage points, from $74.7 \%$ to $62.6 \%$, between May and September 2020 $\left(\chi^{2}=25.89, \mathrm{p}<0.001\right)$.

We fitted a multivariate logistic regression model to data from each sample to identify the correlates of COVID-19 vaccine intentions. Independent variables included demographical variables; an objective measure of numeracy and political ideology; general social trust; prosociality (perceived importance of doing 'things for the benefit of others and society' even at personal cost); general trust in medical and scientific experts; general trust in the government; specific trust in politicians to manage the pandemic; specific trust in (separately) national science advisors, independent scientists and the WHO to 'know the best measures to take in the face of the pandemic'; the perceived efficacy of their own and their country's actions to limit the spread of the virus; perceived likelihood of infection; and worry about COVID-19 (for details on measures, see Methods section and online supplemental table $\mathrm{S} 1$; descriptive statistics are reported in online supplemental table S4 and bivariate correlations in online supplemental figure S1). Continuous measures (ie, all except gender) were scaled and mean centred prior to analysis. Only complete observations were included. Multicollinearity analyses indicated no issues arising from correlated predictors (all variance inflation factor values $<4$ ). To facilitate the interpretation of results, we present ORs in a heat map format in figure 2. Full model results including CIs can be found in online supplemental table S5. Results of models investigating correlates of willingness to recommend a vaccine to vulnerable others are also presented in supplementary materials (online supplemental figure S2, table S6). We fitted an additional multilevel model to the pooled data, adjusting for country, month, days since first case, level of government intervention, total reported deaths and number of cases reported in each country at each time 


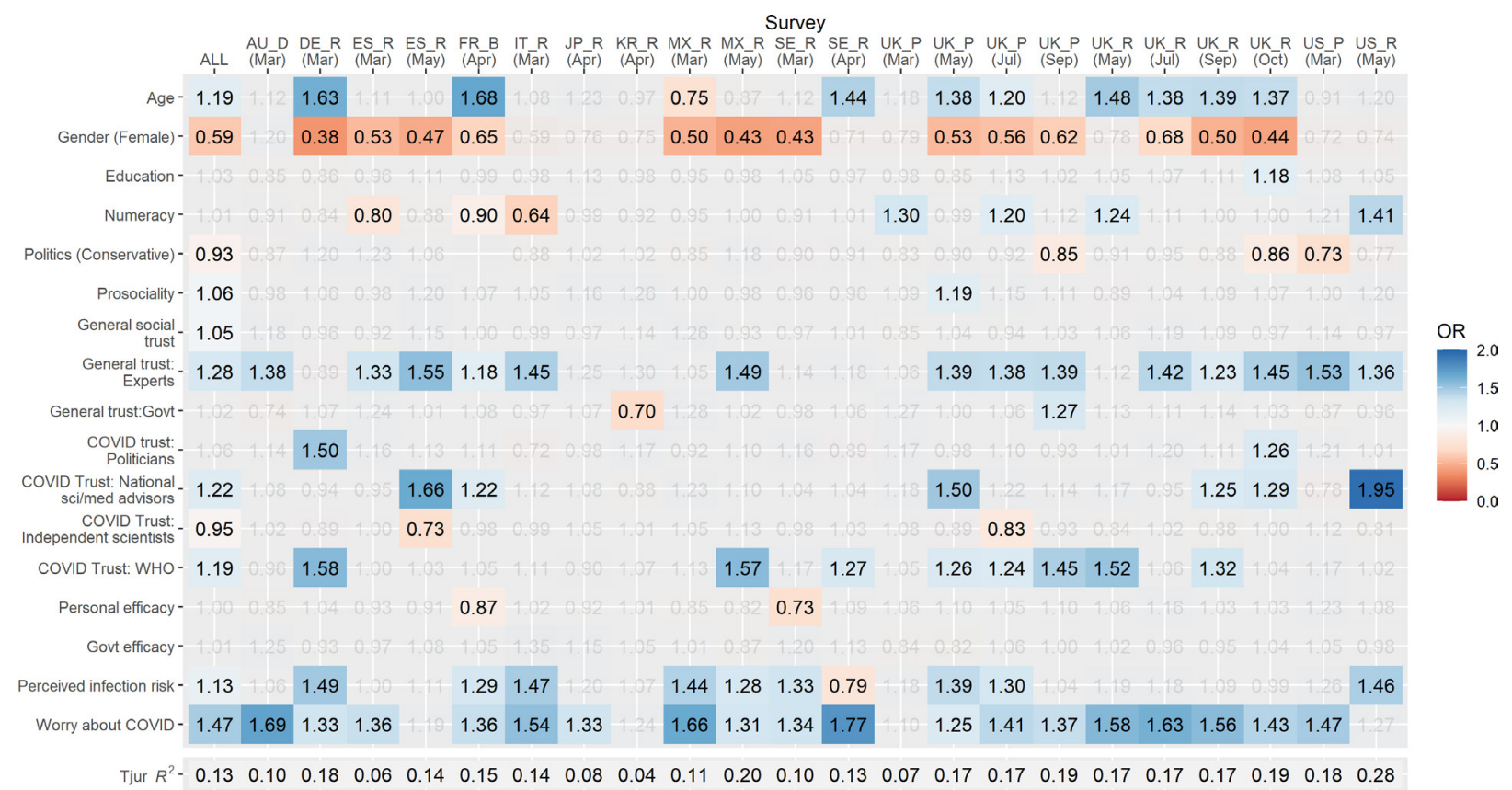

Figure 2 Correlates of vaccine acceptance. Heat map of ORs in multivariate logistic regression model predicting stated vaccine acceptance. Columns represent individual samples, and rows represent independent variables in model. Grey values are non-significant $(\mathrm{p}>0.05)$. Red shading indicates a lower likelihood of reported vaccine acceptance and blue shading a higher likelihood. For space, samples are defined by their two-character ISO country code and a letter denoting participant source (B, BVA; D, Dynata; P, Prolific; and R, Respondi). Political orientation data were not collected in the French sample; this sample is excluded from pooled data.

point (online supplemental table S7). Fixed effects were essentially unchanged from those reported in the simpler pooled model. Due to the low number of groups, estimates of random effects were unreliable. ${ }^{56}$

Considering the most consistent correlates of stated vaccine acceptance across samples, we find that in most samples, individuals who report a higher level of general trust in experts $\left(\mathrm{OR}_{\text {pooled }}=1.28,95 \%\right.$ CI 1.22 to 1.34$)$ or who are more worried about the virus $\left(\mathrm{OR}_{\text {pooled }}=1.47\right.$, $95 \%$ CI 1.41 to 1.53 ) are more likely to say that they would accept a vaccine. In Germany, Spain, Mexico, Sweden (March only) and nearly all UK samples, women are generally less likely to say that they would accept a COVID-19 vaccine if available $\left(\mathrm{OR}_{\text {pooled }}=0.59,95 \%\right.$ CI 0.55 to 0.64) (UK data were over-represented in our pooled sample). As a robustness check, we also fitted the model to the pooled sample with UK data removed and report that the effects of gender, trust in experts and worry remain significant ( $p$ s $<0.001$; see online supplemental table S5). We also note that measures of efficacy, both at the personal $\left(\mathrm{OR}_{\text {pooled }}=1.00,95 \%\right.$ CI 0.96 to 1.05$)$ and country level $\left(\mathrm{OR}_{\text {pooled }}=1.01,95 \%\right.$ CI 0.96 to 1.08$)$, were not significantly associated with reported vaccine acceptance in most samples.

Our results reveal a great deal of heterogeneity in the relevance of correlates across countries but also across time in countries where we conducted multiple surveys. For example, in the USA, only a few consistent associations emerged. Most notably, political conservatism was associated with a lower likelihood to accept a COVID-19 vaccine in March $\left(\mathrm{OR}_{\mathrm{USA}-\mathrm{Mar}}=0.73,95 \%\right.$ CI 0.57 to 0.93 ; $\mathrm{OR}_{\mathrm{USA}-\mathrm{May}}=0.77,95 \% \mathrm{CI} 0.58$ to 1.01$)$, whereas trust in experts $\left(\mathrm{OR}_{\mathrm{USA}-\mathrm{Mar}}=1.53,95 \%\right.$ CI 1.16 to 2.03 ; $\mathrm{OR}_{\mathrm{USA}-\mathrm{May}}=$ $1.36,95 \% \mathrm{CI} 1.02$ to 1.82 ) and personal worry about the virus $\left(\mathrm{OR}_{\mathrm{USA}-\mathrm{Mar}}=1.47,95 \%\right.$ CI 1.17 to $1.87 ; \mathrm{OR}_{\mathrm{USA}-\mathrm{May}}=$ $1.27,95 \%$ CI 0.99 to 1.64$)$ were associated with increased vaccination intentions. In contrast, in the $\mathrm{UK}$, additional factors such as the role of age, gender and prosociality played a significant role. There was also variation over time. For example, although political ideology was not a significant correlate in the UK in May or July 2020, conservatism was associated with lower vaccination intentions from September 2020 onwards (ORs 0.85-0.88), which may be related to increased polarisation. To illustrate the increasing strength of the association between political ideology and vaccine acceptance over time in the UK, in figure 3 , we plot the predicted likelihood of reported vaccine acceptance across the political spectrum (holding all other variables constant).

In the UK, we also report a different pattern of effects when comparing between samples collected via different providers, even where these were collected on the same day (in May, July and September), matched on age and gender and controlling for a range of other demographical variables. This underscores the caution that must be applied when studies generalise results from a single survey sample (particularly an online survey).

In terms of variance explained, the variables in our model explained approximately $10 \%-30 \%$ of the variance in the likelihood of vaccine acceptance versus 

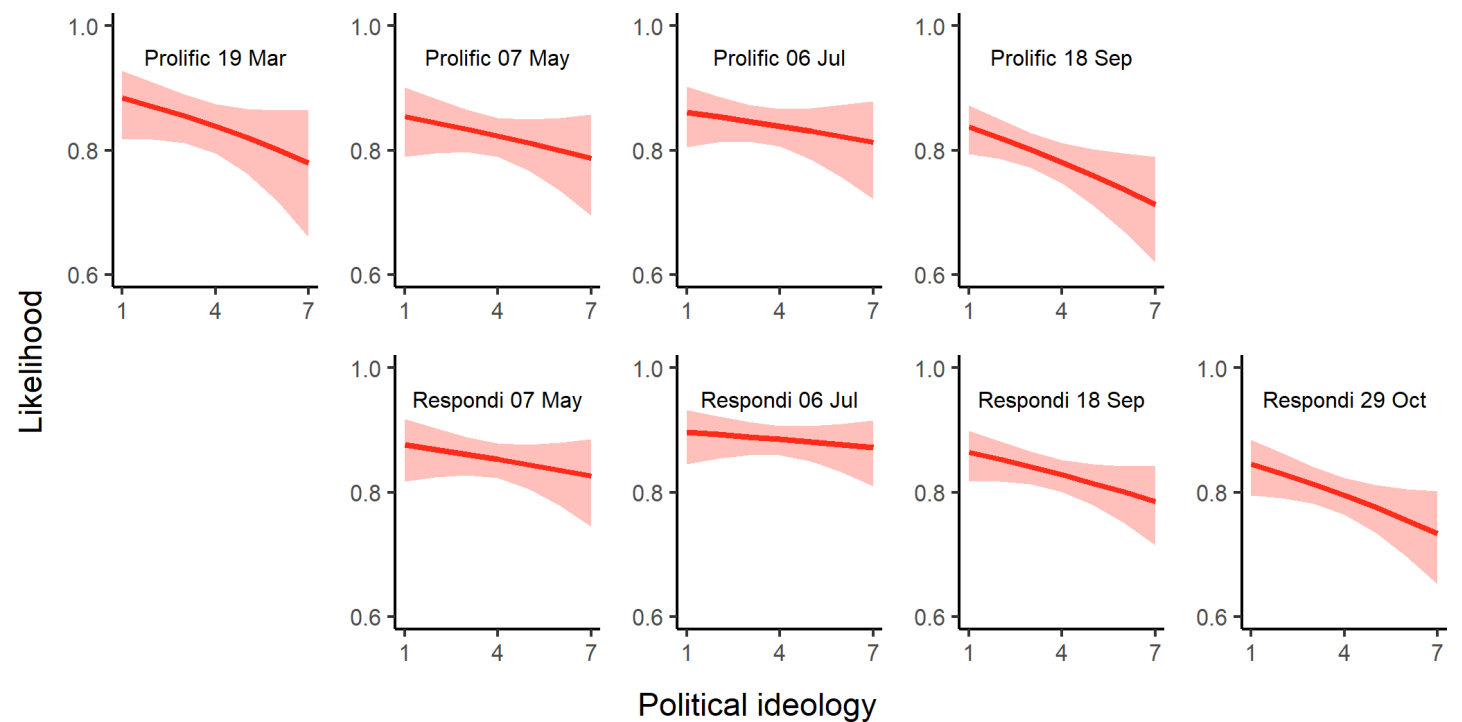

Figure 3 Political ideology and vaccine acceptance in the UK. Predicted likelihood that an individual will accept being vaccinated at varying levels of political ideology ( $1=$ very liberal/left wing and $7=$ very conservative/right wing) in UK samples over time.

refusal, with the exception of samples recruited in South Korea (4\%) and Japan (8\%).

\section{Accounting for general vaccine attitudes}

To examine the extent to which the effects in our model can be accounted for by a negative perception of vaccines in general, we conducted an additional set of analyses. In our three most recent UK surveys, we included a two-item measure of general vaccine attitudes (adapted from Lewandowsky $e t a t^{42}$ ). A comparison of results from models with or without general vaccine attitudes as an independent variable is shown as a heat map in figure 4 . Although attitudes toward vaccination increase the explained variance of our model $\left(\Delta R^{2} 4 \%-9 \%\right)$ and reveal strong significant effects such that more positive attitudes are associated with increased vaccination intentions (ORs 1.69-2.32; full results in online supplemental table S8), the relationships in the original model appear robust and are only minimally attenuated when accounting for generalised attitudes.

\section{DISCUSSION}

Understanding the psychological determinants of vaccine acceptance and hesitancy is crucial during a global pandemic. Across all countries surveyed, between March and September 2020, a substantial proportion of participants (up to $37 \%$ in some countries) said that they would not accept a hypothetical COVID-19 vaccine. People were slightly more likely to say that they would recommend it to vulnerable friends and family members. Considering who is more or less likely to report willingness to be vaccinated against COVID-19, being a man, expressing general trust in those with scientific or medical expertise and worrying about the virus are the most consistent correlates of vaccine acceptance across our samples. It is important to note that hesitancy about a COVID-19 vaccine is not purely attributable to people's attitudes to vaccines in general. Although (in the UK, where we studied it) negative attitudes towards vaccines in general are a significant and important correlate of COVID-19 vaccine refusal, there are clearly additional factors at play in determining public reactions to a COVID-19 vaccine. This broadly aligns with other researches indicating that,

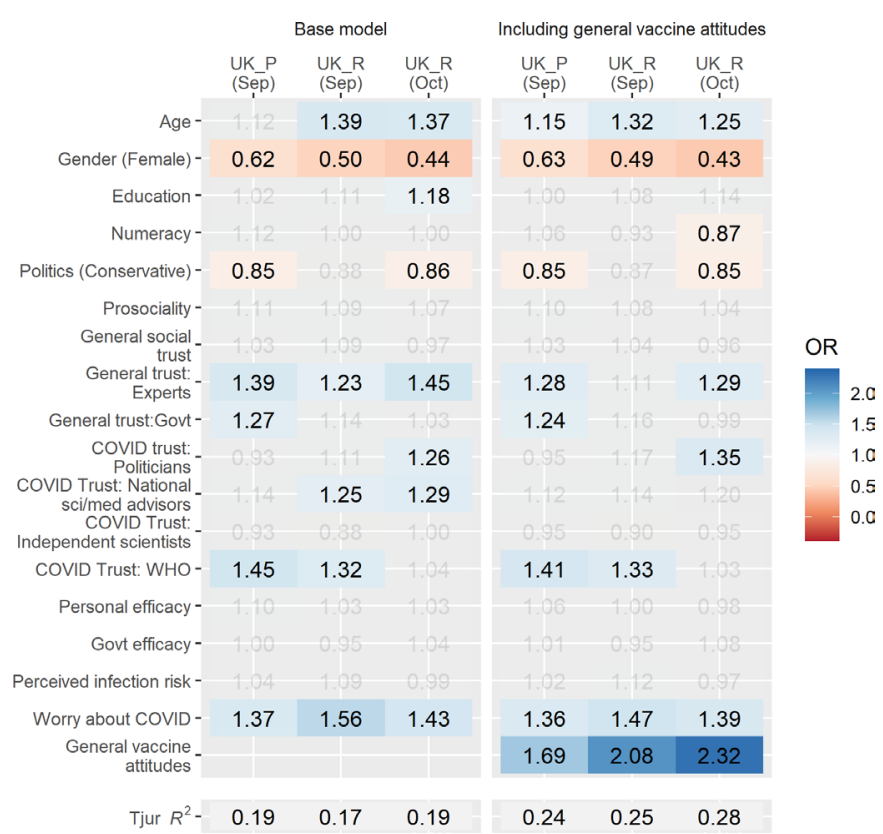

Figure 4 Negative general attitudes towards vaccination do not fully account for relationships in the model. Results of multivariate logistic regression models investigating reported COVID-19 vaccine acceptance in UK samples, excluding (left panel) or including (right panel) general vaccine attitudes as an independent variable. ORs shown are based on scaled variables (other than gender). Grey values are non-significant ( $p>0.05)$. For space, samples are defined by a letter denoting participant source (P, Prolific; R, Respondi). 
for many people, there are concerns specifically around the rapid and novel development processes of COVID-19 vaccines and possible safety issues. ${ }^{36} 57$ Our multivariate analyses show that the bulk of the burden of trust rests on science and medicine. This is in line with other recent studies specifically examining the association between trust in scientists and doctors and COVID-19 vaccine hesitancy. ${ }^{26}{ }^{27}$ Accounting for the other factors in our model, we find that trust in the government (both generally and regarding COVID-19) and general social trust (ie, trust in people) are not significantly associated with vaccine acceptance in most of our samples. Since the period of data collection, more information about COVID-19 vaccines, including their safety and efficacy, has become available. It remains to be seen how this information has shifted vaccine intentions. As the public focus has shifted from vaccine development to the regulatory approval and rollout of vaccines, ${ }^{11}$ it is possible that trust in the government and regulators may play a greater role in individuals' vaccine decision making. However, further research is required to confirm this speculation.

The fact that we saw only a weak link between stated vaccine acceptance and our measure of prosocialityalong with the fact that higher numbers of people said that they would recommend the vaccine to a vulnerable friend or relative than say they would accept it themselves-suggests that the prosocial nature of vaccines may not be recognised by many people. Recent experimental research has shown that emphasising the societal benefits of herd immunity (ie, the need for those who do not see themselves as personally vulnerable to take the vaccine in order to provide protection for those who are) may assist uptake. ${ }^{58}$ However, such strategies depend on vaccines preventing transmission of the virus, rather than just symptoms. There is now preliminary evidence that this is the case for the Moderna and Pfizer-BioNTech vaccines, ${ }^{12}$ but further studies are required to confirm these findings.

The greater reluctance from women to say that they would take a vaccine is in line with other work focusing on acceptance of a potential COVID-19 vaccine ${ }^{18} 19$ and vaccination generally ${ }^{29}$ but has not been adequately explained. Even when general vaccine beliefs are taken into account, however, the gender bias remains. Qualitative work should focus on investigating this further, in order to understand the root of women's concerns about the COVID-19 vaccine. We see very little effect of our measures of personal or governmental efficacy, but this may be related to the fact that a vaccine against COVID-19 was hypothetical at the time of the surveys and our measures did not directly ask about vaccination.

Another important finding highlighted by our repeated samples is that vaccine acceptance appears to be politicised in the USA and is becoming so in the UK. Our US results agree with previous US research focusing on COVID-19 vaccine acceptance, ${ }^{39} 59$ which noted that political conservatives are less accepting of potential COVID-19 vaccines. Our UK results align with those of Maher et al, who, through network analysis, show a pattern of attitudinal alignment over time in a small UK sample, resulting in the emergence of a politically conservative faction expressing less trust in scientists, doctors and vaccines. ${ }^{21}$ Although international research has suggested that political conservatism is correlated with antivaccination attitudes globally, ${ }^{40}$ we did not find that ideology was associated with vaccine acceptance outside of the USA and the UK. However, most other countries were only surveyed in earlier stages of the pandemic (ie, prior to May 2020), and we can therefore not say whether they might have followed a similar pattern to the UK as time went on.

It is possible that misinformation susceptibility ${ }^{6061}$ and conspiracy thinking ${ }^{62}$ underlie the association between ideology and vaccine attitudes to some extent. For example, Motta et $a b^{63}$ find that far-right-wing media outlets have disproportionally spread misinformation during the early stages of the pandemic. Susceptibility to misinformation around COVID-19 was also found in prior research to be associated with measures of vaccine hesitancy. ${ }^{61}$ There is already a proliferation of conspiracy theories focused on specific COVID-19 vaccines. ${ }^{64} 65$ It will be important to tackle these proactively through 'prebunking' methods to inoculate against misinformation. 6667

We must note that our surveys did not examine several sociodemographic factors that could explain additional variance in vaccination intentions; ethnic minority status, socioeconomic status and underlying health conditions have all been shown to be associated with COVID-19 vaccine hesitancy in some contexts. ${ }^{68} 69$ Future research should examine how these factors relate to vaccine confidence and intentions as vaccine campaigns progress.

Finally, we acknowledge that the heterogeneity in our results across time and countries highlights the role that (unmeasured) contextual, country-specific factors play in informing individuals' vaccination attitudes. As noted by the WHO Strategic Advisory Group of Experts on Immunization working group on vaccine hesitancy, individual factors such as trust and risk perception intersect with contextual influences such as culture, media environments and information from local leaders. ${ }^{14}$ Our samples were not truly representative of the general population in each country: although they were quota-balanced on gender and age, the population that responds to an online questionnaire will differ from the general population on several significant characteristics. However, the rank ordering of countries on vaccine acceptance in our study is similar to that of Lazarus $\mathrm{et} \mathrm{al,}{ }^{18}$ which were based on a random stratified sampling approach using several online panel providers. This gives us some confidence in the generalisability of our results, and the fact that our samples were generally larger and included more trustfocused questions makes them useful for exploring these important correlates of vaccine attitudes.

In terms of practical considerations, our finding that trust in scientific and medical institutions is one of the strongest correlates of vaccine acceptance highlights the 
need to work proactively with others from outside of this sphere, such as community and religious leaders, ${ }^{70}$ to open a two-way conversation with those who distrust the scientific and medical establishment. Due consideration must also be given to the accessibility, ${ }^{71}$ format ${ }^{72} 73$ and transparency $^{7475}$ of information provided to the public. Future research should continue to evaluate how to most effectively communicate evidence about vaccination ${ }^{76}$ and should seek to more deeply understand the concerns and needs of those who express hesitancy regarding COVID-19 vaccination. As Bhopal, ${ }^{77}$ commenting on potential COVID-19 mass vaccination efforts, writes, 'open, honest, factual and sensitively conducted public dialogue is now urgent'.

\section{CONCLUSIONS}

Countries around the world face a major evidence communication challenge when it comes to the COVID-19 vaccines that are becoming available. In order to reach a large enough proportion of the population in each country to achieve herd immunity, it is vital to increase the number of people who are willing to take a vaccine. To achieve this, non-pharmaceutical interventions will need to be deployed, ${ }^{78}$ such as communicating trustworthy information about the vaccines via credible sources. In the current research, we have demonstrated across 12 national samples that people's level of worry about COVID-19 and their trust in experts and medical and scientific institutions are key determinants of potential vaccine acceptance. Future research should confirm these findings in experimental settings. We recommend that empirical studies should continue to be carried out alongside qualitative work with different communities to get a rounded understanding of people's concerns and misunderstandings. Only by knowing these can we adequately address them and provide people with the information they need to make a decision that will affect not just their own health, but that of their community as well.

\section{Author affiliations}

${ }^{1}$ Winton Centre for Risk and Evidence Communication, University of Cambridge, Cambridge, UK

${ }^{2}$ Department of Psychology, University of Cambridge, Cambridge, UK

${ }^{3}$ Center of Environmental and Climate Sciences, Lund University, Lund, Sweden

${ }^{4}$ Bordeaux Population Health Research Center, U1219, Inserm, University of

Bordeaux, Bordeaux, France

${ }^{5}$ Pole de Sante Publique, Centre Hospitalier Universitaire de Bordeaux, Bordeaux, France

${ }^{6}$ Direction de la prévention - promotion de la santé, Santé publique France, SaintMaurice, France

\section{Twitter John R Kerr @SciComGuy}

Acknowledgements We would like to thank María del Carmen Climént Palmer, Ban Mutsuhisa, Jin Park and Giulia Luoni for additional translations; the University of Tokyo for their collaboration; and all the participants and those who helped to administer the study.

Contributors Survey instrument development: JRK, CRS, GR, SD, SvdL and AF. Study conceptualisation, design and theoretical framing: JRK, SvdL and AF. Data collection: JRK, CRS, GR, SD, US, CD, PA and AF. Statistical analyses and first draft: JRK, SvdL and AF. Manuscript editing, review and approval: JRK, CRS, GR, SD, US, $\mathrm{CD}, \mathrm{PA}, \mathrm{AF}$ and SvdL.

Funding This study was funded by the Winton Centre for Risk and Evidence Communication, which is supported by the David and Claudia Harding Foundation. Award/grant number is not applicable.

Competing interests None declared.

Patient consent for publication Not required.

Ethics approval This study was approved by the University of Cambridge psychology research ethics committee (PRE.2020.034).

Provenance and peer review Not commissioned; externally peer reviewed.

Data availability statement Data are available in a public, open-access repository. The data and analysis code for this study are available at https://osf.io/ vgez2/

Supplemental material This content has been supplied by the author(s). It has not been vetted by BMJ Publishing Group Limited (BMJ) and may not have been peer-reviewed. Any opinions or recommendations discussed are solely those of the author(s) and are not endorsed by BMJ. BMJ disclaims all liability and responsibility arising from any reliance placed on the content. Where the content includes any translated material, BMJ does not warrant the accuracy and reliability of the translations (including but not limited to local regulations, clinical guidelines, terminology, drug names and drug dosages), and is not responsible for any error and/or omissions arising from translation and adaptation or otherwise.

Open access This is an open access article distributed in accordance with the Creative Commons Attribution Non Commercial (CC BY-NC 4.0) license, which permits others to distribute, remix, adapt, build upon this work non-commercially, and license their derivative works on different terms, provided the original work is properly cited, appropriate credit is given, any changes made indicated, and the use is non-commercial. See: http://creativecommons.org/licenses/by-nc/4.0/.

\section{ORCID iDs}

John R Kerr http://orcid.org/0000-0002-6606-5507

Claudia R Schneider http://orcid.org/0000-0002-6612-5186

Gabriel Recchia http://orcid.org/0000-0002-0210-8635

Sarah Dryhurst http://orcid.org/0000-0002-7772-8492

Ullrika Sahlin http://orcid.org/0000-0002-2932-6253

Carole Dufouil http://orcid.org/0000-0003-2442-4476

Alexandra LJ Freeman http://orcid.org/0000-0002-4115-161X

Sander van der Linden http://orcid.org/0000-0002-0269-1744

\section{REFERENCES}

1 Porterfield C. Global coronavirus death Toll tops 2.5 million - though new fatalities have dropped. Forbes, 2021. Available: https://www. forbes.com/sites/carlieporterfield/2021/02/25/global-coronavirusdeath-toll-tops-25-million-though-new-fatalities-have-dropped/ [Accessed 3 Mar 2021].

2 International Monetary Fund. World economic outlook, October 2020: a long and difficult ascent. Washington, DC, 2020. Available: https://www.imf.org/en/Publications/WEO/Issues/2020/09/30/worldeconomic-outlook-october-2020 [Accessed 29 Nov 2020].

3 Lytras T, Tsiodras S. Lockdowns and the COVID-19 pandemic: what is the endgame? Scand J Public Health 2021;49:37-40.

4 Schoch-Spana M, Brunson EK, Long R, et al. The public's role in COVID-19 vaccination: Human-centered recommendations to enhance pandemic vaccine awareness, access, and acceptance in the United States. Vaccine 2020. doi:10.1016/j.vaccine.2020.10.059. [Epub ahead of print: 29 Oct 2020].

5 Callaway E. What Pfizer's landmark COVID vaccine results mean for the pandemic. Nature 2020. doi:10.1038/d41586-020-03166-8. [Epub ahead of print: 9 Nov 2020].

6 Callaway E. COVID vaccine excitement builds as Moderna reports third positive result. Nature 2020;587:337-8.

7 BBC News. Covid vaccines: how fast is progress around the world? Available: https://www.bbc.co.uk/news/world-56237778 [Accessed 13 Apr 2021].

8 Gomes MGM, Corder RM, King JG, et al. Individual variation in susceptibility or exposure to SARS-CoV-2 lowers the herd immunity threshold. medRxiv 2020. doi:10.1101/2020.04.27.20081893. [Epub ahead of print: 02 May 2020]. 
9 Sanche S, Lin YT, Xu C, et al. High contagiousness and rapid spread of severe acute respiratory syndrome coronavirus 2. Emerg Infect Dis 2020;26:1470-7.

10 Fontanet A, Cauchemez S. COVID-19 herd immunity: where are we? Nat Rev Immunol 2020;20:583-4.

$11 \mathrm{Kim}$ JH, Marks F, Clemens JD. Looking beyond COVID-19 vaccine phase 3 trials. Nat Med 2021;27:205-11.

12 Thompson MG, Burgess JL, Naleway AL, et al. Interim estimates of vaccine effectiveness of BNT162b2 and mRNA-1273 COVID-19 vaccines in preventing SARS-CoV-2 infection among health care personnel, first responders, and other essential and frontline workers - eight U.S. locations, December 2020-March 2021. MMWR Morb Mortal Wkly Rep 2021;70:495-500.

13 Aschwanden C. Five reasons why COVID herd immunity is probably impossible. Nature 2021:591:520-2.

14 WHO. Report of the SAGE Working group on vaccine Hesitancy, 2014. Available: https://www.who.int/immunization/sage/meetings/ 2014/october/1_Report_WORKING_GROUP_vaccine_hesitancy final.pdf [Accessed 23 Nov 2020].

15 WHO. Ten threats to global health in 2019, 2019. Available: https:// www.who.int/news-room/spotlight/ten-threats-to-global-health-in2019 [Accessed 20 Nov 2020].

16 Verger P, Dubé E. Restoring confidence in vaccines in the COVID-19 era. Expert Rev Vaccines 2020;19:991-3.

17 Mesch GS, Schwirian KP. Social and political determinants of vaccine hesitancy: lessons learned from the H1N1 pandemic of 2009-2010. Am J Infect Control 2015;43:1161-5.

18 Lazarus JV, Ratzan SC, Palayew A, et al. A global survey of potential acceptance of a COVID-19 vaccine. Nat Med 2021;27:225-8.

19 Wang J, Jing R, Lai X, et al. Acceptance of COVID-19 vaccination during the COVID-19 pandemic in China. Vaccines 2020;8:482.

20 Frank K, Arim R. Canadians' willingness to get a COVID-19 vaccine when one becomes available: What role does trust play? Stat. Canada, 2020. Available: https://www150.statcan.gc.ca/n1/pub/4528-0001/2020001/article/00043-eng.htm [Accessed 22 Nov 2020].

21 Maher PJ, MacCarron P, Quayle M. Mapping public health responses with attitude networks: the emergence of opinion-based groups in the UK's early COVID-19 response phase. Br J Soc Psychol 2020;59:641-52.

22 Padhi BK A, Almohaithef M. Determinants of COVID-19 vaccine acceptance in Saudi Arabia: a web-based national survey. medRxiv2020:2020.05.27.20114413.

23 Soveri A, Karlsson LC, Antfolk J, et al. Unwillingness to engage in behaviors that protect against COVID-19: the role of conspiracy beliefs, trust, and endorsement of complementary and alternative medicine. BMC Public Health 2021;21:684

24 Palamenghi L, Barello S, Boccia S, et al. Mistrust in biomedical research and vaccine hesitancy: the forefront challenge in the battle against COVID-19 in Italy. Eur J Epidemiol 2020;35:785-8.

25 Petravić L, Arh R, Gabrovec T, et al. Factors affecting attitudes towards COVID-19 vaccination: an online survey in Slovenia. Vaccines 2021:9:247.

26 Thaker J. The persistence of vaccine Hesitancy: COVID-19 vaccination intention in New Zealand. $J$ Health Commun 2021;26:104-11.

27 Jennings W, Stoker G, Willis H. Lack of trust and social media echo chambers predict COVID-19 vaccine hesitancy. medRxiv2021:2021.01.26.21250246.

28 Larson HJ, Cooper LZ, Eskola J, et al. Addressing the vaccine confidence gap. Lancet 2011;378:526-35.

29 de Figueiredo A, Simas C, Karafillakis E, et al. Mapping global trends in vaccine confidence and investigating barriers to vaccine uptake: a large-scale retrospective temporal modelling study. Lancet 2020;396:898-908

30 National Academies of Sciences, Medicine, and Engineering. Trust and confidence at the interfaces of the life sciences and society. A workshop summary. Washington, DC, 2015. https://www.nap.edu/ $\mathrm{read} / 21798$

31 Hartman RO, Dieckmann NF, Sprenger AM, et al. Modeling attitudes toward science: development and validation of the credibility of science scale. Basic App/ Soc Psych 2017;39:358-71.

32 Brewer PR, Ley BL. Whose science do you believe? explaining trust in sources of scientific information about the environment. Sci Commun 2013;35:115-37.

33 Becker MH. The health belief model and sick role behavior. Health Educ Monogr 1974;2:409-19.

34 Rogers RW. A protection motivation theory of fear appeals and attitude Change1. J Psychol 1975;91:93-114.

35 Ling M, Kothe EJ, Mullan BA. Predicting intention to receive a seasonal influenza vaccination using protection motivation theory. Soc Sci Med 2019;233:87-92.
36 Dror AA, Eisenbach N, Taiber S, et al. Vaccine hesitancy: the next challenge in the fight against COVID-19. Eur J Epidemiol 2020;35:775-9.

37 Kelly B, Bann C, Squiers L. Predicting willingness to vaccinate for COVID-19 in the US. JCH impact, 2020. Available: https://jhcimpact. $\mathrm{com} /$ posts/f/predicting-willingness-to-vaccinate-for-covid-19-in-theus [Accessed 22 Nov 2020].

38 Wong LP, Alias H, Wong P-F, et al. The use of the health belief model to assess predictors of intent to receive the COVID-19 vaccine and willingness to pay. Hum Vaccin Immunother 2020;16:2204-14.

39 Kreps S, Prasad S, Brownstein JS, et al. Factors associated with us adults' likelihood of accepting COVID-19 vaccination. JAMA Netw Open 2020;3:e2025594.

40 Hornsey MJ, Harris EA, Fielding KS. The psychological roots of anti-vaccination attitudes: a 24-nation investigation. Health Psychol 2018:37:307-15.

41 Hornsey MJ, Finlayson M, Chatwood G, et al. Donald Trump and vaccination: the effect of political identity, conspiracist ideation and presidential tweets on vaccine hesitancy. J Exp Soc Psychol 2020;88:103947.

42 Lewandowsky S, Gignac GE, Oberauer K. The role of conspiracist ideation and worldviews in predicting rejection of science. PLoS One 2013;8:e75637.

43 Reyna VF, Nelson WL, Han PK, et al. How numeracy influences risk comprehension and medical decision making. Psychol Bull 2009;135:943-73.

44 Betsch C, Schmid P, Heinemeier D, et al. Beyond confidence: development of a measure assessing the $5 \mathrm{C}$ psychological antecedents of vaccination. PLoS One 2018;13:e0208601.

45 Jang WM, Kim U-N, Jang DH, et al. Influence of trust on two different risk perceptions as an affective and cognitive dimension during middle East respiratory syndrome coronavirus (MERS-CoV) outbreak in South Korea: serial cross-sectional surveys. BMJ Open 2020;10:33026.

46 Prolific. Representative samples on prolific. Available: https:// researcher-help.prolific.co/hc/en-gb/articles/360019236753Representative-Samples-on-Prolific [Accessed 19 Oct 2020].

47 Hale T, Angrist N, Goldszmidt R, et al. A global panel database of pandemic policies (Oxford COVID-19 government response Tracker). Nat Hum Behav 2021;5:529-38.

48 Ali $\mathrm{H}$, Hossain MF, Hasan MM, et al. Covid-19 dataset: worldwide spread log including countries first case and first death. Data in Brief 2020;32:106173.

49 Moderna. Moderna ships mRNA vaccine against novel coronavirus (mRNA-1273) for phase 1 study, 2020. Available: https://investors. modernatx.com/news-releases/news-release-details/moderna-shipsmrna-vaccine-against-novel-coronavirus-mrna-1273 [Accessed 1 Apr 2021].

50 University of Oxford. Oxford team to begin novel coronavirus vaccine research, 2020. Available: https://www.ox.ac.uk/news/2020-02-07oxford-team-begin-novel-coronavirus-vaccine-research [Accessed 1 Apr 2021].

51 Adams ben. Pfizer, BioNTech start their COVID-19 vax phase 3 , squaring off with Moderna. Fierce biotech, 2020. Available: https:// www.fiercebiotech.com/biotech/pfizer-biontech-start-their-covidvax-phase-3-squaring-off-moderna [Accessed 1 Apr 2021]

52 National Institutes of Health. Phase 3 clinical testing in the US of AstraZeneca COVID-19 vaccine candidate begins, 2020. Available: https://www.nih.gov/news-events/news-releases/phase-3-clinicaltesting-us-astrazeneca-covid-19-vaccine-candidate-begins [Accessed 1 Apr 2021].

53 Cokely ET, Galesic M, Schulz E. Measuring risk literacy: the Berlin Numeracy test. Judgm Decis Mak 2012;7:25-47.

54 Lipkus IM, Samsa G, Rimer BK. General performance on a numeracy scale among highly educated samples. Med Decis Making 2001:21:37-44

55 Lundmark S, Gilljam M, Dahlberg S. Measuring generalized trust. Public Opin Q 2016;80:26-43.

56 Bryan ML, Jenkins SP. Multilevel modelling of country effects: a cautionary tale. Eur Sociol Rev 2016;32:3-22.

57 Campbell D. Protecting others and record of vaccines main reasons to get Covid Jab, POLL shows. guardian, 2020. Available: https:// www.theguardian.com/society/2020/nov/30/covid-protecting-othersand-record-of-vaccines-main-reasons-to-get-jab

58 Betsch C, Böhm R, Korn L, et al. On the benefits of explaining herd immunity in vaccine advocacy. Nat Hum Behav 2017;1:0056.

59 Carpiano RM. Demographic differences in US adult intentions to receive a potential coronavirus vaccine and implications for ongoing study. 
60 Calvillo DP, Ross BJ, Garcia RJB, et al. Political ideology predicts perceptions of the threat of COVID-19 (and susceptibility to fake news about it). Soc Psychol Personal Sci 2020;11:1119-28.

61 Roozenbeek J, Schneider CR, Dryhurst S, et al. Susceptibility to misinformation about COVID-19 around the world. $R$ Soc Open Sci 2020;7:201199.

62 Linden S, Panagopoulos C, Azevedo F. The paranoid style in American politics revisited: an ideological asymmetry in Conspiratorial thinking. Polit Psychol 2020:pops.12681.

63 Motta M, Stecula D, Farhart C. How Right-Leaning media coverage of COVID-19 facilitated the spread of misinformation in the early stages of the pandemic in the U.S. Can J Pol Sci 2020;53:335-42.

64 Reuters. Fact check: Dr. Fauci was not the first CEO and other false claims about biotech company Moderna. Reuters, 2020. Available: https://uk.reuters.com/article/uk-factcheck-moderna-fauci-gates/ fact-check-dr-fauci-was-not-the-first-ceo-and-other-false-claimsabout-biotech-company-moderna-idUSKBN25S5GD [Accessed 23 Nov 2020].

65 May L. Antivaxxers share conspiracy theories after pfizer announcement. Dly. mail, 2020. Available: https://www.dailymail.co. uk/news/article-8934447/Antivaxxers-share-conspiracy-theoriesPfizer-announcement.html [Accessed 23 Nov 2020].

66 Roozenbeek J, van der Linden S, Nygren T. Prebunking interventions based on 'inoculation' theory can reduce susceptibility to misinformation across cultures. Harvard Kennedy Sch Misinformation Rev 2020;1.

67 Jolley D, Douglas KM. Prevention is better than cure: addressing antivaccine conspiracy theories. J App/ Soc Psychol 2017;47:459-69.
$68 \mathrm{Kim} \mathrm{D}$. Associations of Race/Ethnicity and other demographic and socioeconomic factors with vaccination during the COVID-19 pandemic in the United States. medRxiv2021:2021.02.16.21251769.

69 Williams L, Flowers P, McLeod J, et al. Social patterning and stability of intention to accept a COVID-19 vaccine in Scotland: will those most at risk accept a vaccine? Vaccines 2021;9:17.

70 Jarrett C, Wilson R, O'Leary M, et al. Strategies for addressing vaccine hesitancy - a systematic review. Vaccine 2015;33:4180-90.

71 O'Neill O. Accountability, trust and informed consent in medical practice and research. Clin Med 2004;4:269-76.

72 Schwartz LM, Woloshin S, Welch HG. Using a drug facts box to communicate drug benefits and harms: two randomized trials. Ann Intern Med 2009;150:516-27.

73 Brick C, McDowell M, Freeman ALJ. Risk communication in tables versus text: a registered report randomized trial on 'fact boxes'. $R$ Soc Open Sci 2020;7:190876.

74 Blastland M, Freeman ALJ, van der Linden S, et al. Five rules for evidence communication. Nature 2020;587:362-4.

75 van der Bles AM, van der Linden S, Freeman ALJ, et al. The effects of communicating uncertainty on public trust in facts and numbers. Proc Natl Acad Sci U S A 2020;117:7672-83.

76 Kerr JR, Freeman ALJ, Marteau TM, et al. Effect of information about COVID-19 vaccine effectiveness and side effects on behavioural intentions: two online experiments. Vaccines 2021;9:379.

77 Bhopal RS. COVID-19 zugzwang: potential public health moves towards population (herd) immunity. Public Health Pract 2020;1:100031.

78 Bavel JJV, Baicker K, Boggio PS, et al. Using social and behavioural science to support COVID-19 pandemic response. Nat Hum Behav 2020;4:460-71 